\title{
CONCEPTUAL MODEL FOR MANAGING RESERVOIR USING INTELLIGENT DECISION SUPPORT SYSTEM
}

\author{
Pratap Singh Solanki ${ }^{1}$, Siddharth Roman ${ }^{2}$, Swapnil Dhumal $^{3}$, Akshay Dhadave $^{4}$, Omkar Potekar $^{5}$ \\ ${ }^{1}$ Guide, Central Water and Power Research Station, Pune, Maharashtra, India \\ ${ }^{2}$ Student of Computer Science, Zeal College of Engg., Maharashtra, India \\ ${ }^{3}$ Student of Computer Science, Zeal College of Engg, Maharashtra, India \\ ${ }^{4}$ Student of Computer Science, Zeal College of Engg, Maharashtra, India \\ ${ }^{5}$ Student of Computer Science, Zeal College of Engg, Maharashtra, India
}

\begin{abstract}
The reservoir water level is controlled by dam gates. If water comes to a reservoir in huge quantity more than its full capacity then the gates are required to be opened. But if water is less then gates are closed to store water for future use. Some questions are always there in front of decision makers and dam engineers such as how to decide whether to open or close the dam gates. A solution of above problems needs a dedicated program based on Intelligent Decision Support System (DSS) using latest IT tools to decide that how much quantity of water is reaching to the reservoir in advance in the event of rainfall upstream and in what period, so accordingly Dam gates could be managed. In an absence of such type of program, floods are damaging the property year after year. For management of dam efficiently, it requires taking fast and precise decisions after analyzing available data and making predictions so that flood situation can be avoided. It should be flexible enough and able to handle water level in the reservoir and Gate management efficiently.
\end{abstract}

Key Words: DSS, Decision Support System, Regression Analysis, Dam Gates Management $* * *$

\section{INTRODUCTION}

In the year 2006, a major human tragedy and property loss was caused due to a massive flood in the city Surat, Gujrat, India. It was $3^{\text {rd }}$ major flood since 1994. It was caused due to the sudden release of huge amount of water from Ukai Dam and almost $80 \%$ of the city went under water.[2] The improper management of reservoir led to such tragedy. So there was need of improvement in dam management. In the last few years, some steps have been taken towards facing these types of situations. The reservoir water level is controlled by dam gates. If water comes to a reservoir in huge quantity more than its full capacity then the gates are required to be opened. But if water is less then gates are closed to store water for future use. Some questions are always there in front of decision makers and dam engineers: 1. In the event of floods if the gate operator suddenly opens the gates there will be huge flooding downstream which will damage the mankind and agricultural fields. So in what regulatory manner he should open the gates to release water from the reservoir?

2. How much water should be released from gates? Because, If suppose he opens the gate then what is the guarantee that water will surely come to the reservoir in future.

3. For how long he has to keep the gates open to ensure that the reservoir water level is under control?

For solving such types of problems, a dedicated program can be written. In this paper we are discussing the concept model for such kind of program which is an Intelligent Decision Support System.

But first let's clear some basic concepts related to dams.

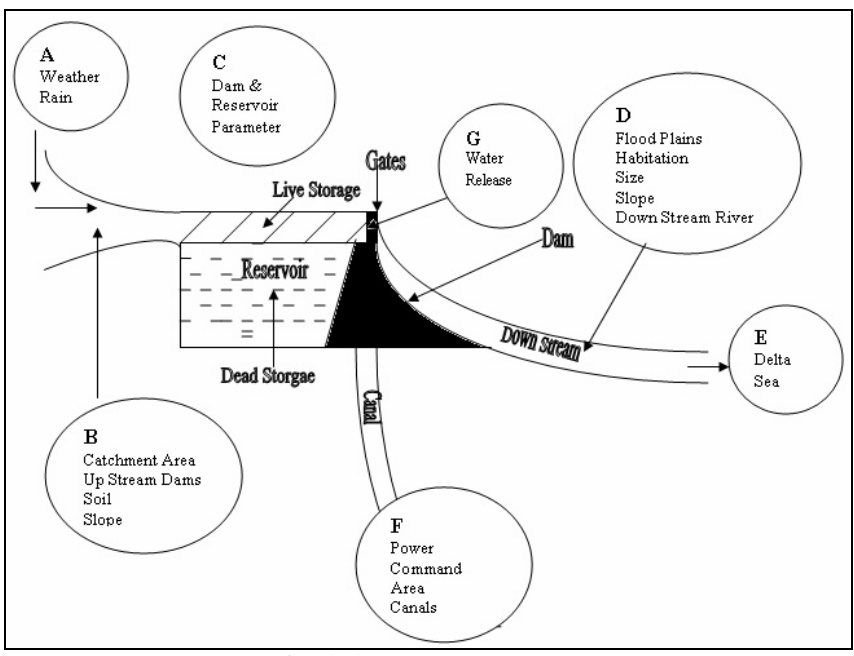

Fig 1.1 Dam Basics [2]

General Terms [6]:

Reservoir: It is an artificial (man-made) or natural lake or it is a water body due to the construction of a dam, used to store the water for future use. Size and design of the reservoir may depend on the purpose. A reservoir is used for Irrigation, navigation, recreation, Power generation, soil conservation, industries, water supply, Flood Control, Development of wildlife and fish etc.

Watershed: A watershed is the area of land that drains all of the streams and rainfall to a common outlet. Watershed sometimes referred as a catchment area or drainage basin. It may consist surface water and all underlying ground water. 
Full Reservoir Level: Highest water level to which the water surface will rise during normal operation condition.

Minimum Pool Level: The lowest level up to which water can be withdrawn on a specific condition.

Live Storage: water which stored between to Full reservoir level and the minimum pool level is known useful water storage. This water is used to supply as per demand for the specific period.

Maximum Water Level: Maximum level to which the water surface will rise when the design flood passes over the spillway.

Dead Storage: Water below the minimum pool level is called dead storage. No water can be drained from the reservoir by gravity.

\section{EXISTING SYSTEMS [2]}

Over the years the government has tried to improve the dam management using automation. But these procedures takes time. Also the cost associated with these types of systems is high and hence cannot be installed at all places.

Now there are some issues such as,

1. There exist some System for prediction of reservoir water level. This existing system is based on the discharge measurement made at a few Km upstream and not on the basis of rainfall occurred at far upstream.

2. The main drawback of the existing system is that the warning time available to manage the gates is very less. Also there is no computer program available to make decision that when and how much gates are to be opened in case of heavy rainfall.

3. Sometimes these systems of discharge measurement may fail due to bad weather.

4. The operators thus have to depend on the wireless message sent by Flood Cell of central Water Commission for decision making.

5. Decisions are made based on set rule curves and no dedicated computer program is available.

There is scope of enhancements in the existing systems such as

Different dam stations should able to work independently rather than depending on the central office.

\section{PROPOSED METHODOLOGY}

Every dam has its own catchment area. The daily rainfall in this area is measured using rain gauge. Rain gauge is basically a glass tube to measure precipitation.

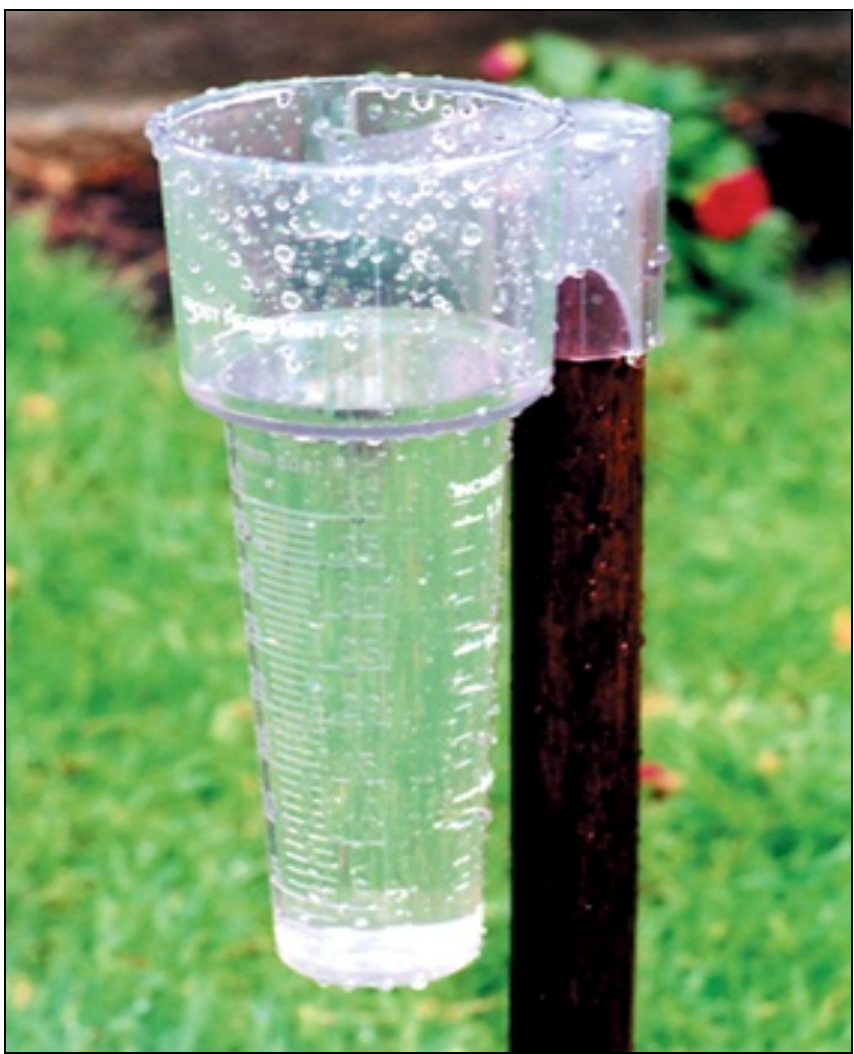

Fig 2.1 Rain Gauge

There are many number rain gauge stations in the catchment area. As the catchment area is too large it can be divided in number of parts for based on upstream and downstream better understanding.

Each of these divided parts will have some rain gauge stations associated with them.

First of all we need to find out the discharge of water from these parts using data from rain gauge stations. On the basis of previous ten years of data we can create an equation to convert the rainfall into discharge.

After applying regression analysis to this data we get the regression coefficients using which we can predict the run off.

Now after calculating discharges we are able to find out the total inflow of water.

This daily inflow of water can be converted to volume of water reaching to the reservoir. So if we know the initial level of reservoir we can update the current water level.

If this level is greater than reservoir's full capacity then we can alert the authorities.

Information Communication Technology (ICT):

ICT deals with the data transmission, storage, information retrieval and processing of data. The advancement in the ICT leads to develop the application for processing of huge amount of data using statistical method or data mining Technology. The communication of information to different ends is handled by various available networking tools. Presently, there are different types of software development tools available for automation of the manual system. An advanced and efficient GUI (Graphical User Interface) may be developed using .NET Framework which has all the necessary tools such as VB.NET. In this proposed work, we 
are dealing with the rainfall data. These data can be either entered by user, using developed GUI or import through from source file to RDBMS e.g. MS Access Database.

\section{Data Mining:}

Data Mining is a field of computer science which deals with extraction of knowledge from provided data. Data mining techniques are useful in making predictions and group wise analysis of data. Regression analysis is one of the data mining techniques used for prediction.

\section{Regression Analysis:}

Regression analysis is a method of finding relationships among dependent and independent variables. Regression is the statistical study of the change in the value over the specific period of time. It is used in data mining tasks such as predicting and forecasting. There are basically two types of regression analysis linear and non-linear. Here we are using linear regression analysis in which we are finding points near the straight line.

Using this method we are able to find out the inflow of water in advance.

This DSS can further be extended to manage water supply efficiently as the reservoir water is supplied for different purposes such Industrial use, Irrigation Purpose, Agricultural use etc.

\subsection{CONCEPTUAL MODEL OF DSS}

\section{DSS will mainly consist of following components:}

1. Water level predictor: Its function is to predict the increase or decrease in the water level of the reservoir. It measures discharge and converts it into volume of water.

2. Decision Maker: Suggesting the decision to whether open or close the dam gates.

3. Data Analyzer: Statistical as well regression analysis of data.

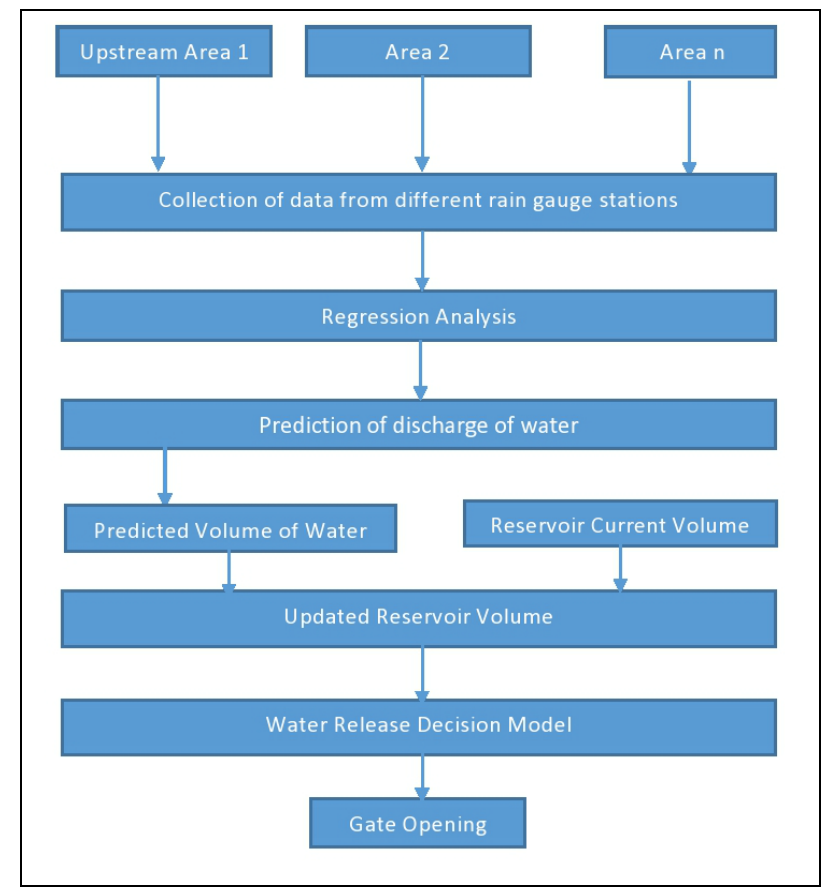

Fig 3.2 Conceptual model of DSS

\subsection{ADVANTAGES OF USING DSS}

1. These decisions can very well be taken in advance as the runoff can be predicted.

2. Dam operators will be able act on the decision suggested and flood situations can be avoided.

3. Reservoir can be managed more efficiently.

4. Human mind cannot take decisions under pressure but DSS can work round the clock.

\subsection{FUTURE SCOPE}

This system can be enhanced further to automate the management of dam gates. Flood alerts can be sent via SMS. It can be integrated with web applications for accessing information easily.

\section{CONCLUSION}

Data mining is the process to extracting the hidden information from the existing database for predicting the future behavior. The advancement of ICT technology also contributing to carried-out the various research and experiment work in the water resource sector. In this paper we tried to explore the possibility to develop the Intelligent Decision Support System using data mining technology to predict the expected volume of water to reach the reservoir. This predicted volume of water will help to management to take fast decision in advance, for operation of the dam gates to avoid the flood situation or to store more water in reservoir. An Intelligent Decision Support System can be developed using above knowledge. These types of DSS may be very helpful for proper decision making and efficient reservoir management.

\section{ACKNOWLEDGEMENT}

We are thankful to Mr. S. Govindan, Ex. Director, CWPRS, Pune who entrusted on us and provided an opportunity to associate with premium research institute. Finally we would like to thank Prof. S. M. Sangve and Prof. R. S. Suryawanshi for their throughout support and guidance.

\section{REFERENCES}

[1]. D. S. Bundela,A. Sarangi , "DECISION SUPPORT SYSTEMS IN WATER RESOURCES MANAGEMENT A REVIEW"

[2]. Dileep Mavalankar,Amit Kumar Srivastava , "Lessons from Massive Floods of 2006 in Surat City: A framework for Application of MS/OR Techniques to Improve Dam Management to Prevent Flood", INDIA,2008

[3]. Wan Hussain Wan Ishak, Ku Ruhana Ku-Mahamud and Norita Md Morwawi, "Conceptual Model of Intelligent Decision Support System Based on Naturalistic Decision Theory for Reservoir Operation during Emergency Situation", IJCEE-IJENS Vol: 11 No: 02,April 2011

[4]. Muhammad Aqil, Ichiro Kita, Akira Yano, and Nishiyama Soichi (2006). "Decision Support System for Flood Crisis Management using Artificial Neural Network", International Journal of Intelligent Technology, Vol. 1, Number 1, 2006, ISSN 1305-6417 
[5] Kyu-Cheoul Shim; Darrell G. Fontane, M.ASCE; and John W. Labadie, M.ASCE (2002). "Spatial Decision Support System for Integrated River Basin Flood Control," Journal of Water Resources Planning and Management, May/June 2002, pp 190

[6]. www.nptel.com

[7]. www.india-wris.nrsc.gov.in

\section{BIOGRAPHIES}

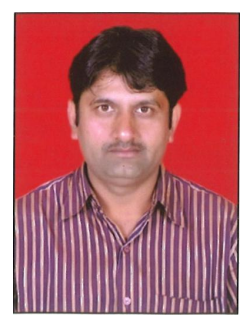

\section{Pratap Singh Solanki}

The author is well known Scientist -B at Central Water And Power Research Station, Pune. He has an excellent knowledge of Computer Science and working in the research field of Water Resource Sector. He is guiding for the studies related to this project work.

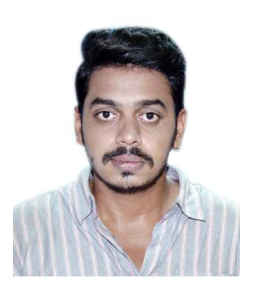

\section{Siddharth Roman}

The author is currently pursuing B.E. in computer Science from University of Pune.

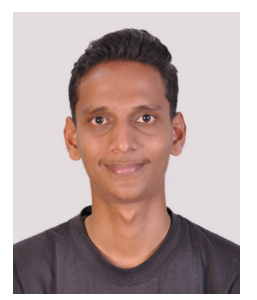

\section{Omkar Potekar}

The author is currently pursuing B.E. in computer Science from University of Pune.

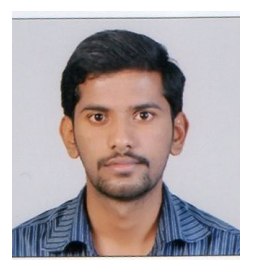

\section{Swapnil Dhumal}

The author is currently pursuing B.E. in computer Science from University of Pune.

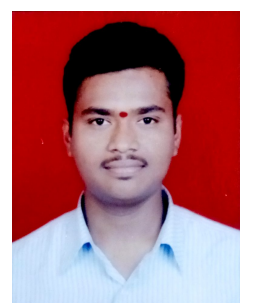

\section{Akshay Dhadave}

The author is currently pursuing B.E. in computer Science from University of Pune. 